(2) Open Access Full Text Article

\title{
Appendectomy in a child with cyclic neutropenia in profound neutropenic episode
}

This article was published in the following Dove Press journal:

Therapeutics and Clinical Risk Management

17 August 2015

Number of times this article has been viewed

\author{
Nedeljka Glavan' \\ Jelena Roganović \\ Lana Glavan-Gačanin ${ }^{3}$ \\ Nives Jonjić ${ }^{4}$ \\ 'Department of Pediatrics \\ Surgery, ${ }^{2}$ Department of Pediatrics \\ Hematology and Oncology, University \\ Hospital Centre Rijeka, ${ }^{3}$ Department \\ of Obstetrics and Gynecology, \\ University Hospital Centre Rijeka, \\ ${ }^{4}$ Department of Pathology, School \\ of Medicine, University of Rijeka, \\ Rijeka, Croatia
}

\begin{abstract}
Our experience in the treatment of a 4-year-old boy with cyclic neutropenia who was admitted for urgent appendectomy is described. The postoperative course was uneventful with high daily doses of granulocyte colony-stimulating factor and antimicrobial therapy. The purpose of this report is to highlight the importance of immediate appendectomy in neutropenic patients, wherein low absolute neutrophil count should not be considered as a contraindication for urgent surgical procedure.
\end{abstract}

Keywords: cyclic neutropenia, appendectomy, absolute neutrophil count (ANC)

\section{Introduction}

Cyclic neutropenia is a rare hereditary disorder with an estimated incidence of 0.5-1 case per million population. The disorder is characterized by episodes of profound neutropenia with a typical cycle length of 21 days. The most common infections encountered during neutropenic nadir are pharyngitis, gingivitis, and periodontitis. More serious complications can occasionally occur including pneumonia, mastoiditis, and bacterial cutaneous and subcutaneous infections. ${ }^{1}$ Infections that require operative procedure are of particular concern due to the increased risk of potentially lethal complications. As appendicitis is the most common cause of acute abdomen in children, it may, although rarely, occur in patients with cyclic neutropenia. It is extremely delicate for the surgeon to decide on the operative management, in particular on the timing of the operation considering the low absolute neutrophil count (ANC). Profound neutropenia implies a risk for the patient in case of surgery as well as in case of a delay in operative procedure.

\section{Case report}

A 4-year-old boy suffering from cyclic neutropenia was admitted to the Department of Pediatric Surgery, Clinical Hospital Centre Rijeka, with a 24-hour history of high fever and right lower abdominal pain suspicious of acute appendicitis. The patient's medical history revealed that the cyclic neutropenia may be caused by the neutrophil elastase gene (ELA2) mutation, which additionally puts him in the category of patients who are at increased risk of severe infectious complications. The boy was regularly treated with granulocyte colony-stimulating factor (G-CSF), initially at a dose of $3 \mu \mathrm{g} / \mathrm{kg}$ but required gradual dose increase to $15 \mu \mathrm{g} / \mathrm{kg}$ to obtain therapeutic response. In the past 2 years, he experienced ANC nadir to 0 for every 3 months and also a lack of response to G-CSF. These episodes were accompanied by high fever with tonsillopharyngitis, aphthous stomatitis, and pneumonia, mostly requiring hospitalization.
Correspondence: Nedeljka Glavan Department of Pediatrics Surgery, Clinical Hospital Centre Rijeka, Istarska 43, 51000 Rijeka, Croatia Tel +385 (0)5I 62I 420 Email neda.glavan@ri.t-com.hr 

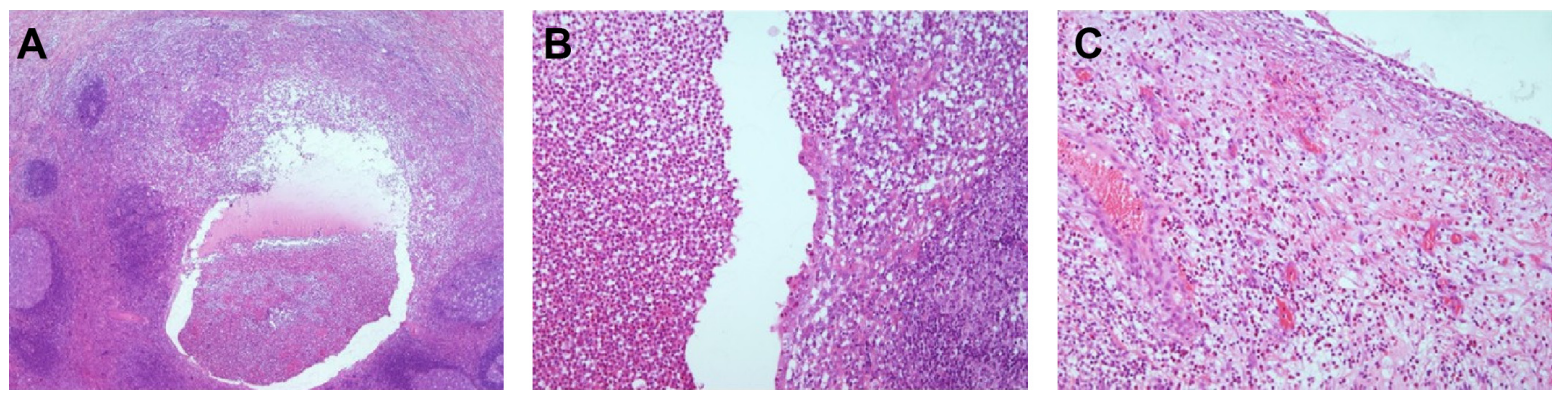

Figure I Diffuse acute appendicitis with the intraluminal leukocytes (A), ulceration and infiltration of leukocytes in the mucosa (B), and fibrinopurulent exudate on the surface (C).

In the morning of the day of surgery, his $\mathrm{ANC}$ was 0 , and G-CSF at a dose of $15 \mu \mathrm{g} / \mathrm{kg}(300 \mu \mathrm{g})$ subcutaneously was prescribed; the same afternoon, the patient's general condition improved, ANC was 196, and C-reactive protein was elevated $(92.9 \mathrm{mg} / \mathrm{L})$. As abdominal pain persisted, the pediatrician referred him to the surgeon.

Upon admission in the evening, the child was febrile with overt signs of acute abdomen, and ANC was 135. After consultation of a pediatric hematologist, another G-CSF at a dose of $15 \mu \mathrm{g} / \mathrm{kg}$ was administered, and urgent appendectomy was performed. Histopathology findings confirmed phlegmonous suppurative appendicitis (Figure 1).

Postoperatively, the patient received parenteral antibacterial and antifungal therapy with daily ANC determination and G-CSF administration. ANC values were declining on the first four postoperative days and started rising on postoperative day 5. On postoperative day 7, ANC increased significantly (Table 1). G-CSF therapy was discontinued in consultation with hematologist. The patient was discharged in a good general condition on postoperative day 8 . Informed consent was obtained from mother.

Table I Absolute neutrophil count and dose of granulocyte colony-stimulating factor during hospitalization

\begin{tabular}{lll}
\hline Time & ANC & G-CSF (I5 $\mu$ g/kg s.c.) \\
\hline Day 0 (admission) & 0 & $300 \mu \mathrm{g}$ \\
$\quad$ Morning & 196 & - \\
Afternoon & 135 & $300 \mu \mathrm{g}$ \\
$\quad$ Evening - appendectomy & & \\
Postoperative day & 162 & $300 \mu \mathrm{g}$ \\
I & 60 & $300 \mu \mathrm{g}$ \\
2 & 64 & $300 \mu \mathrm{g}$ \\
3 & 74 & $300 \mu \mathrm{g}$ \\
4 & 249 & $300 \mu \mathrm{g}$ \\
5 & 546 & $300 \mu \mathrm{g}$ \\
6 & 5,236 & - \\
7 & 3,960 & - \\
8
\end{tabular}

Abbreviations: ANC, absolute neutrophil count; G-CSF, granulocyte colonystimulating factor; s.c., subcutaneously.

\section{Discussion}

Cyclic neutropenia is a rare, autosomal dominantly inherited disorder with variable presentation. ${ }^{2}$ It is characterized by periodic neutropenia that recurs every $14-35$ days, although over $90 \%$ of patients exhibit a typical cycle length of 21 days. ${ }^{1}$ In most patients, neutrophil counts oscillate between mild and severe neutropenia, with ANC nadir of $100 / \mu \mathrm{L}$ for 3-6 days in each cycle. The duration of neutropenia may vary among patients but is usually consistent in each patient.

The disorder is caused by mutations in the gene for neutrophil elastase (ELA2 or ELANE) on chromosome 19p13.3. ${ }^{3}$ Genetic diagnosis is positive in $90 \%-100 \%$ of patients. ${ }^{4}$ Clinical manifestations usually begin during the 1 st year and can persist for many years but tend to decrease with age, together with the cycling. There is a wide spectrum of disease severity, ranging from an asymptomatic disease to the life-threatening sepsis. ${ }^{5}$ The severity of infections tends to parallel the neutropenic nadir. ${ }^{1}$ The commonest infections are pharyngitis, gingivitis, and stomatitis, which demand medical attention and sometimes hospitalization. More serious bacterial infections include pneumonia, mastoiditis, cellulitis, and intestinal perforation with peritonitis, often complicated by clostridial sepsis. ${ }^{6}$ Infectious deaths have been reported in $10 \%$ of patients. ${ }^{1}$ Conditions requiring operative procedure pose additional problems in these patients due to the potentially severe surgical complications. One such condition is acute abdomen, and here are literature data on deaths of patients in the neutropenic phase of the cycle following acute disease accompanied by abdominal pain. ${ }^{5}$ Although appendicitis is the most common cause of acute abdomen, it is important to know that other conditions can present with clinical manifestations of acute abdomen but do not require surgery. These conditions include but are not limited to streptococcal pharyngitis, pneumonia, mesenteric adenitis, constipation, Crohn's disease, and neutropenic enterocolitis in severely myelosuppressed patients. Taking all these in consideration, 
it becomes evident that differential diagnosis and surgeon's experience are crucial.

Recombinant G-CSF has been very efficacious in raising neutrophil count, preventing infections, and alleviating infectious complications. ${ }^{1}$ Because of the rarity and heterogeneity of the disorder, there are no universally accepted guidelines regarding the dose and duration of G-CSF treatment. Most hematologists recommend maintaining ANC $>500 / \mu \mathrm{L}$. The majority of patients responds to $\mathrm{G}-\mathrm{CSF}$ doses in the range of $2-3 \mu \mathrm{g} / \mathrm{kg}$, administered subcutaneously either daily or on alternate days. ${ }^{4}$ Some patients require higher G-CSF doses to maintain the desired peripheral blood neutrophil count. Our patient had a history of cyclic neutropenia and regular administration of G-CSF that reduced the extent of neutropenia and accompanying infections. He was presented in emergency setting, with acute abdomen due to phlegmonous appendicitis and in profound neutropenic phase. The optimal treatment strategy for this condition has not been established. To our knowledge, there are only two published cases, ${ }^{7,8}$ and most reports are for neutropenic patients with malignant diseases. One approach is nonoperative management with an initial course of intravenous antibiotics (third-generation cephalosporin, amikacin, and metronidazole) and G-CSF administration with ANC rising to $>500$. Conservative therapy can be associated with longer hospital stays and recurrent appendicitis or perforation. Early appendectomy involves considerable risk of infectious complications, and the decision to operate can be exceedingly difficult. Surgical management of our patient, in addition to the administration of G-CSF and intravenous antimicrobial therapy, resulted in complete and rapid postoperative recovery.

Surgery is acceptable as first-line treatment in such cases.

\section{Conclusion}

The reported case clearly emphasizes that low neutrophil count in a child with cyclic neutropenia and acute appendicitis should not be considered a contraindication for urgent appendectomy.

\section{Author contributions}

Dr Glavan treated the patient, conceived and designed the case report, coordinated the evaluation of the case, drafted the manuscript, and approved the final manuscript as submitted. Professor Roganović as pediatric hematologist involved in the treatment of the patient, participated in the draft of the manuscript and approved the final manuscript as submitted. Dr Glavan-Gačanin reviewed and edited the manuscript and approved the final manuscript as submitted. Professor Jonjić supervised and gave expert opinion on the case, revised the manuscript, and approved the final manuscript as submitted. All authors contributed toward data analysis, drafting and critically revising the paper and agree to be accountable for all aspects of the work.

\section{Disclosure}

The authors report no conflict of interest in this work.

\section{References}

1. Dale DC, Cottle TE, Fier CJ, et al. Severe chronic neutropenia: treatment and follow-up of patients in the severe chronic neutropenia international registry. Am J Hematol. 2003;72(2):82-93.

2. Dale DC, Bolyard AA, Aprikyan A. Cyclic neutropenia. Semin Hematol. 2002;39:89-94.

3. Horwitz MS, Corey SJ, Grimes HL, Tidwell T. ELANE mutations in cyclic and severe congenital neutropenia:genetics and pathophysiology. Hematol Oncol Clin North Am. 2013;27(1):19-41.

4. Horwitz MS, Duan Z, Korkmaz B, Lee HH, Mealiffe ME, Salipante SJ. Neutrophil elastase in cyclic and severe congenital neutropenia. Blood. 2007;109(5):1817-1824.

5. Palmer SE, Stephens K, Dale DC. Genetics, phenotype, and natural history of autosomal dominant cyclic hematopoiesis. Am J Med Genet. 1996;66(4):413-422.

6. Bar-Joseph G, Halberthal M, Sweed Y, Bialik V, Shoshani O, Etzioni A. Clostridium septicum infection in children with cyclic neutropenia. J Pediatr. 1997;131(2):317-319.

7. Goldschneider KR, Forouhar FA. Cyclic neutropenia: a case of asymptomatic appendicitis. Ann Clin Lab Sci. 1989;19(6):429-434.

8. Langer JC, Papa MZ, Hoffman MA, Loeff DS, Pearl RH, Filler RM. Cyclic neutropenia with colonic perforation and nonhealing colocutaneous fistula. J Pediatr Surg. 1990;25(3):346-348.
Therapeutics and Clinical Risk Management

\section{Publish your work in this journal}

Therapeutics and Clinical Risk Management is an international, peerreviewed journal of clinical therapeutics and risk management, focusing on concise rapid reporting of clinical studies in all therapeutic areas, outcomes, safety, and programs for the effective, safe, and sustained use of medicines. This journal is indexed on PubMed Central, CAS,

\section{Dovepress}

EMBase, Scopus and the Elsevier Bibliographic databases. The manuscript management system is completely online and includes a very quick and fair peer-review system, which is all easy to use. Visit http://www.dovepress.com/testimonials.php to read real quotes from published authors. 